\title{
Tentative qualitative and quantitative analysis of phenolic compounds in leaf extract from Carica papaya Linn. plant growing in Uganda
}

\author{
JADWIGA NOWAK ${ }^{1}$, ANNA K. KISS $^{2}{ }^{\oplus}$, CHARLES WAMBEBE ${ }^{1}$, ESTHER KATUURA $^{3 \odot}$, \\ ŁUKASZ KUŹMA*4ْ
}

\author{
${ }^{1}$ Department of Pharmacology \& Therapeutics \\ School of Biomedical Sciences, College of Health Sciences, Makerere University \\ P. O. Box 7062 \\ Kampala, Uganda \\ ${ }^{2}$ Department of Pharmacognosy and Molecular Basis of Phytotherapy \\ Medical University of Warsaw \\ Banacha 1 \\ Warsaw, Poland \\ ${ }^{3}$ Department of Plant Sciences, Microbiology and Biotechnology \\ College of Natural Sciences, Makerere University \\ P. O. Box 7062 \\ Kampala, Uganda \\ ${ }^{4}$ Department of Biology and Pharmaceutical Botany \\ Medical University of Łódź \\ Muszyńskiego 1 \\ 90-151 Łódź, Poland \\ *corresponding author: e-mail: lukasz.kuzma@umed.lodz.pl
}

\section{Summary}

Introduction: Carica papaya L. belongs to Caricaceae family. It is an evergreen tree or shrub with usually unbranched trunk. Previous studies on the methanolic leaf extract of this plant proved the antibacterial, cytotoxic, anticancer and antioxidant effects indicative of promising therapeutic potentials.

Methods: Chromatographic and spectroscopic techniques along with high performance liquid chromatography quantitative analysis were performed to isolate, tentatively identify and quantify polyphenolic compounds in $\mathrm{MeOH}$ extract of C. papaya leaves. UHPLC-DAD-ESI-MS/MS and UHPLC-DAD methods were adopted for qualitative and quantitative analysis respectively. In the case of polyphenol separation, some reference substances were isolated by preparative HPLC. 
Results: Six polyphenols were isolated and quantified from C. papaya leaf extract, including three phenolic acids: derivatives of caffeic acid, $p$-coumaric acid, ferulic acid and three flavonoids: quercetin dirhamnosylhexoside, kaempferol dirhamnosyl-hexoside, quercetin 3-O-rutinoside. Among them quercetin dirhamnosyl-hexoside was significantly higher $(1.9 \mathrm{mg} / \mathrm{g}$ extract $)$ than other identified compounds.

Conclusion: The results of present study provide a new data on polyphenols composition of C. papaya plant derived from Uganda and promote research on its possible standardization and use as a dietary supplement and/or herbal medicine.

Key words: Carica papaya L., polyphenols, methanolic extract, UHPLC-DAD, UHPLC-DAD-MS, preparative-HPLC

\section{Słowa kluczowe: Carica papaya L., polifenole, ekstrakt metanolowy, UHPLC-DAD, UHPLC-DAD- MS, metoda preparatywnej HPLC}

\section{INTRODUCTION}

Medicinal plants have been used globally for centuries to promote the quality of life and to treat diseases. According to the World Health Organization (WHO) estimations, about three-quarters of the world's population currently use herbs and other forms of natural medicines to treat various diseases [1]. During their normal growth, plants contain and produce specific type of chemical compounds, namely phytochemicals or secondary metabolites. These secondary metabolites are not only involved in the growth and reproduction of the plant, but often play an important role in plant defence mechanism [2]. Constituents of plants may vary both qualitatively and quantitatively according to the ecology, weather, age, time of collection and other factors [3]. Extracts and/or fractions containing these bioactive compounds have been investigated as potential therapeutic agents with their phytoconstituents being isolated either for direct use as drug, e.g. phytosterols, saponins, flavonoids, alkaloids, essential oils or phenolic compounds, or as a novel compounds which can be structurally modified for therapeutic purposes [4].

Carica papaya L. is an evergreen plant belonging to Caricaceae family, which is classified as a green tree or shrub with a usually unbranched trunk, containing white latex in all parts. The stem is cylindrical, hollow with prominent leaf scars and spongyfibrous tissue [5]. It has an extensive rooting system. The flowers are tiny, yellow, funnel-shaped, solitary or clustered in the leaf axils while the leaves are spirally arranged and clustered near apex of trunk [5]. Large-sized and cylindrical-shaped fruits have fleshy orange pulp, hollow berry, thin yellowish skin during ripening. The seeds are numerous, small, black, round, covered with gelatinous aril. Small latex vessels extend throughout the tree and are particularly abundant in fruit that has reached full size but has not yet begun to ripen $[5,6]$.

The extracts of this plant are used as a diuretic because of their ability to promote urine production (roots and leaves). Furthermore, the anthelmintic (leaves and seed), choleretic and hepatoprotective (fruit) properties as well as antimalarial actions are reported. The juice is also used for the treatment of warts, cancer, tumours, corns and skin defects, while the root is used to help tumours of the uterus. The ripe fruits are used in wounds of urinary tracts, ringworms, skin disease psoriasis and colon cancer -the fiber of papaya is able to bind cancer-causing toxins in the colon and keep them away from the healthy colon cells [7].

In C. papaya plant above 5000 compounds are identified and documented. Some of them were assumed to have anticancer properties (e.g., carotenoids, phenolics and glucosinolates). Previous in vitro studies of this plant revealed the cytotoxic and anticancer activities on different cancer cell lines [8]. C. papaya contains papain that breaks down the fibrin of cancer cell wall into amino acid derivative, a strong antioxidant lycopene as well as isothyocynate which is effective against breast, lung, colon, pancreas, prostate cancer and leukaemia. These enzymes have been proven to inhibit both formation and development of cancer cells. Rumiyati and Ariyani (2006) observed the cytotoxicity of a protein fraction containing ribosomeinactivating proteins isolated from C. papaya against cancer cell lines [9]. Rashed and Fouche (2013) noticed that the petroleum extract of $C$. papaya aerial parts has significant anticancer activities on breast cancer cells [10]. According to the earlier studies, the extracts of $C$. papaya plant have also other interesting activities, such as analgesic [11], antipyretic, antinociceptive, anti-inflammatory [12], antimicrobial [13] and cardiovascular [14]. 
Although the phytochemical analyses of C. papaya extracts were carried out in previous studies and were focused on flavonoids [15], carotenoids and other phenolic compounds [16], as well as sterols and fatty acids [17], there is no data concerning the quantitative analysis of bioactive polyphenols in C. papaya leaf extracts from the plant growing in Uganda. Botanical and herbal preparations contain a single or multiple medicinal plants. The knowledge about the chemical structure of the main active phytocompounds in the plant material is very important in the context of standardization [18]. To achieve this goal, it is crucial to determine the content of the identified active substances in the tested botanicals [18]. Therefore, in this work, for the first time, the alcoholic extract of C. papaya leaves was investigated qualitatively and quantitatively using the UHPLC-MS and UHPLCDAD methods, respectively.

\section{MATERIAL AND METHODS}

\section{Plant material}

Plant materials were collected from an organic certified farm in Luwero, Uganda and taken to Makarere University Herbarium (MHU) for authentication. The voucher specimen of analysed plant material was allocated numbers JN/ 002.

\section{Preparation of the plant material and extraction procedure}

The plant material was collected in the morning, washed and air dried in the shade at ambient temperature $\left(25-30^{\circ} \mathrm{C}\right)$ for 6 days to obtain constant weight. The dried material (leaves) was pulverized (using mortar and pestle) and kept in air tight container at room temperature until the extraction was done.

Plant powder $(500 \mathrm{~g})$ was soaked in $2.5 \mathrm{l}$ of methanol for 3 days. The acquired solution was filtered using Whatman filter paper (No. 1) and concentrated in vacuo at the temperature lower than $45^{\circ} \mathrm{C}$ to obtain the green gum crude residue. The obtained methanolic extracts were stored in $-4^{\circ} \mathrm{C}$ until use for phytochemical analysis.

\section{UHPLC-DAD-ESI-MS qualitative analysis of C. papaya leaf extract}

Two milligrams of C. papaya crude extract was dissolved in methanol and qualitatively analysed by UHPLC-DAD-ESI-MS/MS. Chromatographical analysis was performed on a UHPLC-3000 RS system (Dionex, Germany) with DAD detection and an AmaZon SL ion trap mass spectrometer with an ESI interface (Bruker Daltonik GmbH, Germany). Separation was performed on a Zorbax SB-C18 column $(150 \times 2.1 \mathrm{~mm}, 1.9 \mu \mathrm{m})$ (Agilent, USA). The mobile phase consisted of water (A) and acetonitrile (B) and the following gradients were applied: $0-60 \mathrm{~min}, 5-40 \% \mathrm{~B}$. The LC eluate was introduced into the ESI interface without splitting and compounds were analysed in negative ion mode with the following settings: nebulizer pressure of $40 \mathrm{psi}$; drying gas flow rate of $9 \mathrm{l} / \mathrm{min}$; nitrogen gas temperature of $300^{\circ} \mathrm{C}$; and a capillary voltage of $4.5 \mathrm{kV}$. The mass scan ranged from 100 to $2200 \mathrm{~m} / \mathrm{z}$. The UV spectrum was recorded in the range of 200-400 $\mathrm{nm}$ and chromatogram was acquired at $325 \mathrm{~nm}$. Compounds were identified by comparing their mass spectroscopic data with those described in the literature.

\section{Preparative-HPLC isolation of the identified compounds}

In order to isolate some of the polyphenols present in C. papaya L. leaves, which standards are not commercially available, the leaf extract was subjected to preparative-HPLC separation. For this purpose, plant methanolic extract was dissolved in $25 \mathrm{ml}$ of methanol and water $(8: 2, v / v)$. Afterwards, $25 \mathrm{ml}$ of cyclohexane was added to the solution and vortexed for $3 \mathrm{~h}$ to eliminate chlorophyl and non-polar contaminants. Water-methanolic part of solution was separated from non-polar cyclohaxane fraction and concentrated in vacuo. The purified polar fraction was filtered through a $0.22 \mu \mathrm{m}$ syringe filter and chromatographically separated using preparative-HPLC chromatograph equipped with the binary pump (Gilson), the column thermostat (JetStream 2 Plus), and the UVVis detector (Knauer). The working parameters, with exception of the column thermostat, were controlled by LP-chrom 2.51 software. The polar part of the extract was separated on the semi-preparative HPLC column $(250 \times 9.0 \mathrm{~mm}$ id; $5.0 \mu \mathrm{m}$; Agilent Technologies) at $24^{\circ} \mathrm{C}$, using the two-ingredients mobile phase consisted of water and acetonitrile, both acidified by formic acid $(0.1 \%)$. The chromatographical isolation was carried out by linear gradient according to the following program: 0-90 min: 0-100\% acetonitrile at the flow rate of $2.5 \mathrm{ml} \mathrm{min}^{-1}$. The UV detection of the isolated compounds was done at $325 \mathrm{~nm}$. 


\section{UHPLC-DAD quantitative determination of polyphenols in the plant extract}

The five parts, $5 \mathrm{mg}$ each, of extracted gum residue were dissolved in $1 \mathrm{~mL}$ of methanol, filtered through $0.22 \mu \mathrm{m}$ syringe filters and quantitatively analyzed by UHPLC method for polyphenols identified in this study. Analyses were performed in Agilent Technologies 1290 Infinity apparatus equipped with diode array detector (DAD), a binary solvent delivery pump, vacuum degasser, an autosampler and thermostated column compartment. Zorbax Eclipse Plus $\mathrm{C}_{18}$ column $(100 \times 2.1 \mathrm{~mm}$ id; $1.8 \mu \mathrm{m}$; Agilent Technologies $)$ and pre-column $(100 \times 2.1 \mathrm{~mm}$ id; $1.8 \mu \mathrm{m}$; Agilent Technologies) at $40^{\circ} \mathrm{C}$ was used to separate constituents. The mobile phase consisted of $0.1 \%$ formic acid in acetonitrile $(v / v)$ (solvent $\mathbf{A}$ ) and $0.1 \%$ formic acid $(v / v)$ in water (solvent B). A gradient program was applied as follows: $0-16 \mathrm{~min}$ 0-10\% A; 16-25 min 10-13\% A, 25-37 min 13-30\% A; $37-40$ min $30-95 \%$ A; $40-45 \min 95 \%$ A. The column was equilibrated with $0 \% \mathrm{~A}$ for $3 \mathrm{~min}$ between injections. The flow rate was $0.3 \mathrm{ml} \mathrm{min}^{-1}$ and injection volume $1 \mu \mathrm{l}$. The detection wavelength was set at $325 \mathrm{~nm}$. The identity of the determined phytocompounds with those detected by the UHPLC-DAD-ESI-MS method was confirmed on the basis of the UV $\left(\lambda_{\max }\right)$ spectra data. The content of identified polyphenols was calculated on the basis of the calibration curves created by UHPLC analysis and expressed as $\mathrm{mg} / \mathrm{g}$ of dry extract. To determine the calibration curve for quantification of active compounds in C. papaya leaves, commercial standards (Roth), namely caffeic acid , $m$-coumaric acid, ferulic acid and non-commercial standard of flavonoid glycosides (isolated by preparative-HPLC in this study) were used.

Ethical approval: The conducted research is not related to either human or animal use.

\section{RESULTS AND DISCUSSION}

\section{Identification of phenolic compounds in C. papaya leaf extract}

The full scan negative ionization mode of the C.papa$y a$ leaf extract showed a total of six compounds, identified as phenolic acids and flavonoids (fig. 1, tab. 1).

Table 1.

UPLC-DAD-ESI-MS data of detected and identified polyphenolic compounds in C. papaya methanolic leaf extract.

\begin{tabular}{llcccc}
\hline & \multicolumn{1}{c}{ Compounds } & Retention time $[\mathrm{min}]$ & $\mathrm{UV}\left[\lambda_{\max }\right.$ in nm] & {$[\mathrm{M}-\mathrm{H}]^{-}$} & Fragmentation ions \\
\hline 1 & Caffeic acid derivative & 23.1 & 327 & 295 & 179,133 \\
\hline 2 & Quercetin dirhamnosyl-hexoside & 25.2 & 254,355 & 755 & $609,463,301$ \\
\hline 3 & Kaempferol dirhamnosyl-hexoside & 27.6 & 265,350 & 739 & $593,575,285$ \\
\hline 4 & Coumaric acid derivative & 28.3 & 315 & 279 & 163 \\
\hline 5 & Quercetin rhamnosyl-hexoside & 29.1 & 260,355 & 609 & 301 \\
\hline 6 & Ferulic acid derivative & 30.3 & 327 & 309 & 193,149 \\
\hline
\end{tabular}

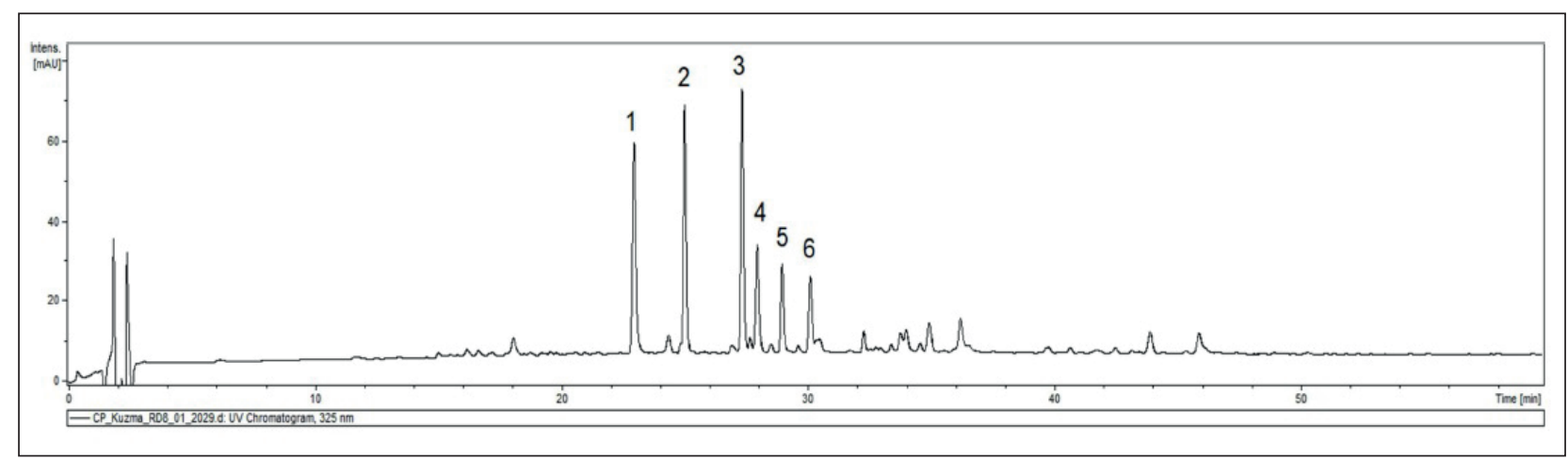

Figure 1.

The chromatogram of the qualitative UHPLC-DAD-ESI-MS analysis of C. papaya methanolic leaf extract 1 - caffeic acid derivative, 2 - quercetin dirhamnosyl-hexoside, 3 - kaempferol dirhamnosyl-hexoside, 4 - coumaric acid derivative, 5 - quercetin rhamnosyl-hexoside (rutin), 6 - ferulic acid derivative 


\section{Phenolic acids}

The peak 1 presented a $[\mathrm{M}-\mathrm{H}]^{-}$ion at $m / z 295$ and fragments corresponding to its aglycone $(\mathrm{m} / z$ 179) and caffeic acid (fig. 2$)$ derivative $(\mathrm{m} / z$ 133) as reported in previous studies [19]. Peak 4 showed molecular ion at $[\mathrm{M}-\mathrm{H}]^{-} 279$ and fragments corresponding to coumaric acid residue (Fig. 3), which has been also noted by Regoset et al. (2009) in the same plant species [20]. Peak 6 with its molecular ion value at $[\mathrm{M}-\mathrm{H}]^{-} 309$ demonstrated fragmentation 193 and 149, indicating that this phytocompound is a ferulic acid (fig. 4) derivative [21].

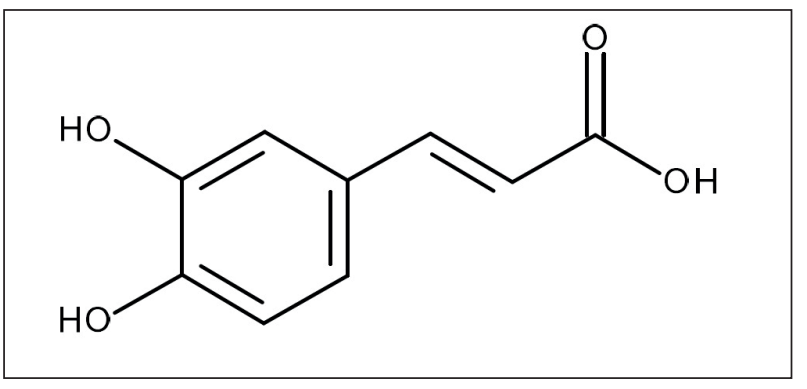

Figure 2.

The chemical structure of caffeic acid

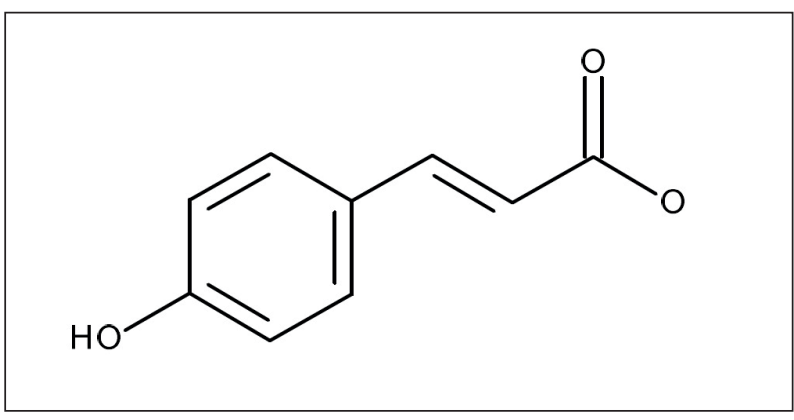

Figure 3.

The chemical structure of coumaric acid

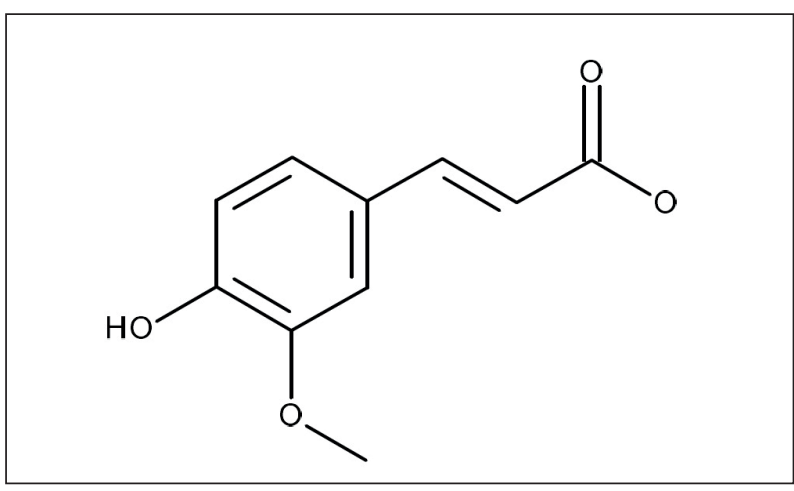

Figure 4.

The chemical structure of ferulic acid

\section{Flavonoids}

The molecular ion at $[\mathrm{M}-\mathrm{H}]^{-} 755$ and the fragmentation of the peak 2 suggest that this compound is quercetin (fig. 5) dirhamnosyl-hexoside [22] while Peak 3 compound was identified as flavonoid kaempferol (fig. 6) dirhamnosyl-hexoside with its value of molecular ion at $[\mathrm{M}-\mathrm{H}]^{-} 739$ [23]. Peak 5 was recorded as a compound with its molecular ion at $[\mathrm{M}-\mathrm{H}]^{-} 609$ and the main fragmentation ion 301 and corresponds to quercetin (fig. 5) 3-O-hexoside [24].

All identified constituents are the phytochemicals belonging to the polyphenols, a class of natural compounds widespread throughout the plant kingdom. The content of determined compounds is expressed in $\mathrm{mg} / \mathrm{g}$ of the dry extract (fig. 7) and their retention times in quantitative UHPLC analysis are shown in figure 8.

Although quantitative analysis of C. papaya flavonoids had been done before, plant material used originated from the other part of the world, resulting in a different spectrum and content of these metabolites [15]. The reason may be due to various environmental conditions of plant growth, like light and photoperiod, temperature, soil, water and

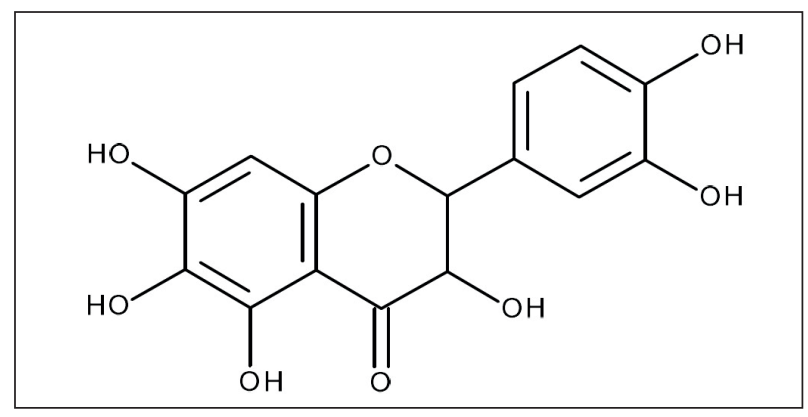

Figure 5.

The chemical structure of quercetin

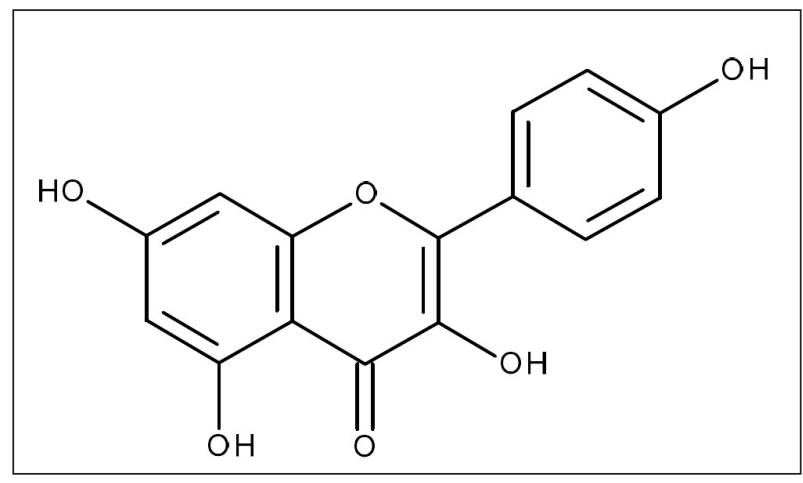

Figure 6.

The chemical structure of kaempferol 


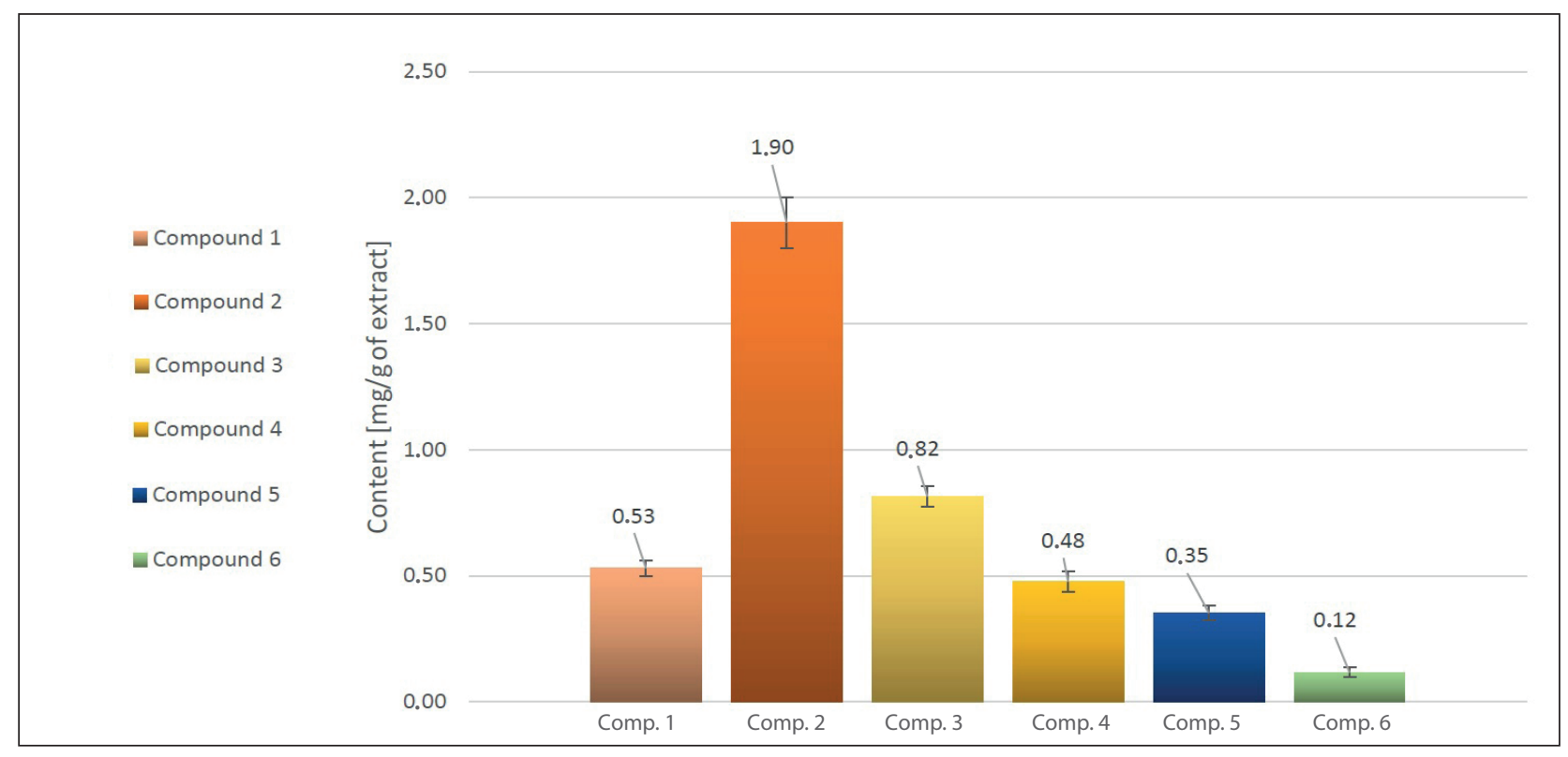

Figure 7.

Content of polyphenols in C. papaya leaf extract. Values are reported as mean $\pm \mathrm{SE}$ ( $\mathrm{n}=15$ of UHPLC analyses) compound 1 - caffeic acid derivative, compound 2 - quercetin dirhamnosyl-hexoside, compound 3 - kaempferol dirhamnosyl-hexoside, compound 4 - coumaric acid derivative, compound 5 - quercetin rhamnosyl-hexoside, compound 6 - ferulic acid derivative



Figure 8.

The chromatogram of the quanitative UHPLC analysis of C. papaya methanolic leaf extract 1 - caffeic acid derivative, 2 - quercetin dirhamnosyl-hexoside, 3 - kaempferol dirhamnosyl-hexoside, 4 - coumaric acid derivative, 5 - quercetin rhamnosyl-hexoside, 6 - ferulic acid derivative

salinity [25] and other factors, like mycorrhizal fungi or plant genotypes [26]. This study, for the first time, performed the tentative qualitative and quantitative analysis of C. papaya plant growing in Uganda and have proven a different plant phenolic composition to those investigated in previous research [26].

Among all six qualitatively and quantitatively determined polyphenolic secondary metabolites, quercetin dirhamnosyl-hexoside was found in the highest amounts. The content of this flavanol glycoside was $1.9 \mathrm{mg} / \mathrm{g}$ of the dry extract (fig. 7). The level of other phytocompounds was within limit of $0.1-$ $0.8 \mathrm{mg} / \mathrm{g}$ of the dry extract (fig. 7). In contrary to this study results, a similar research on Indonesian C. $p a-$ paya demonstrated kaempferol 3-( $2^{G}$-rhamnosylrutinoside) to be most abundant flavonoid $(7.23 \mathrm{mg} / \mathrm{g})$ in plant methanolic leaf extract, and total flavonoid content to be $12.64 \mathrm{mg} / \mathrm{g}$, comparing to much lower value of $3.6 \mathrm{mg} / \mathrm{g}$ isolated in this work [15].

All analysed polyphenolic constituents have been known for their biological activities. Flavonols are the most common flavonoids in the plant kingdom, and their main representatives are quercetin and kaempferol. These compounds are present in glycosylated forms, which was also confirmed in our study. All flavanols in C. papaya leaf extract have a carbohydrate moieties, with most common sugars being rhamnose and glucose [27]. The flavonoids are known for their 
antioxidant activities and are still of current scientific interest. Their antioxidant capacity is based on their functional groups as acceptors of the negative charges of free radicals and are intensively studied due to their benefits for human health and treatment of diseases, including cancer and cardiovascular diseases [27] . These natural compounds are reported in the context of their potential antiviral, anti-allergic, antiplatelet, anti-inflammatory, antitumor, antioxidant effect and treatment of neurodegenerative disorders [28]. Quercetin and its derivatives are often described as the most widely used bioflavonoid in the treatment of metabolic disease and inflammation, which corresponds to the hepatoprotective and diuretic properties of $C$. papaya extract $[7,28]$. The relatively high content of the sum of quercetin derivatives $(2.25 \mathrm{mg} / \mathrm{g}$ of the dry extract) confirmed in our study points out once again towards medicinal potential of studied botanical material. Among identified and quantified flavonoids, kaempferol dirhamnosyl-hexoside and its derivatives is reported as a potent chemopreventive agent for cancer disease [29]. Kaempferol suppressed UVB-induced cyclooxygenase-2 (COX-2) protein expression in mouse skin epidermal and attenuated the UVB-induced transcriptional activities of COX-2 [29].

Phenolic acids, namely caffeic, coumaric and ferulic acid derivatives, are the second group of identified and quantified compounds in this study (tab. 1, fig. 7). Total content of these constituents in tested material is about $1.1 \mathrm{mg} / \mathrm{g}$ of the dry extract. Caffeic acid derivative is the most abundant compound $(0.53 \mathrm{mg} / \mathrm{g}$ of the dry extract) and similarly to the remaining phenolic acids determined in $C$. papaya leaf, it exhibits antimicrobial and cytotoxic activities [30]. Antioxidant properties of this compound have been also reported to prevent inflammation, cancer and neurodegenerative diseases [31]. Ferulic acid and its derivatives are well known for their antioxidant, anti-inflammatory, antiviral, antiallergic, antimicrobial, antithrombotic, anticarcinogenic, and hepatoprotective actions [32]. Once again, isolated phenolic acids, just like flavonoids, vary in quantity and quality, compared to those identified in other studies. For example, caffeic and cinnamic acids are the only two acids identified using the HPLC technique in a C. papaya grown in Malaysia [33].

\section{CONCLUSION}

Taking into account the results obtained in this study, the following conclusions can be draw. Namely,
Carica papaya leaves extract, derived from the plant growing in Uganda, for the first time was used for the identification and quantification of polyphenols, especially flavonoids and phenolic acids. The results presented in this study show a vast differences in flavonoid and phenolic acids composition between the same plant species grown in different geographical locations.

New data on the polyphenol composition of C. papaya leaf of Ugandan origin opens up research perspectives on the possible standardization of this material [18] and its potential use as a dietary supplement and/or herbal medicine.

\section{ACKNOWLEDGMENT}

This work was supported by grant No. 503/3-01201/503-31-001-19-00 of Medical University of Łódź, Poland.

Conflict of interest: Authors declare no conflict of interest.

\section{REFERENCES}

1. Dhiman A, Sharma K, Sharma A, Sindhu P. A review on the status of quality control and standardization of herbal drugs in India. Drug Dev Ther 2016; 7(2):107-112. doi: http://dx.doi. org/10.4103/2394-6555.191165

2. Hussein RA, El-Anssary AA. Plant Secondary Metabolites: The Key Derivers of the Pharmacological Actions of Medicinal Plants. In: Philip Builders, ed. Herbal Medicine. London. IntechOpen 2019:12-30. doi: http://dx.doi.org/10.5772/ intechopen.76139

3. Zhang L, Wang X, Guo J, Xia Q, Zhao G, Zhou $\mathrm{H}$, Xie F. Metabolic profiling of Chinese tobacco leaf of different geographical origins by GC-MS. J Agric Food Chem 2013; 61(11):2597-2605. doi: http://dx.doi.org/10.1021/jf400428t

4. Saini SA, Dhiman AN, Nanda SA. Pharmacognostical and phytochemical studies of Piper betle Linn. leaf. Int J Pharm Pharm Sci 2016; 8(5):222226.

5. Silva JD, Rashid Z, Nhut DT, Sivakumar D, Gera A, Souza MT, Tennant P. Papaya (Carica papaya 
L.) biology and biotechnology. Tree For Sci Biotech 2007; 1(1):47-73.

6. Maisarah AM, Asmah R, Fauziah O. Proximate analysis, antioxidant and anti- proliferative activities of different parts of Carica papaya. J Tissue Sci Eng 2014; 4(2):267-274. doi: http://dx.doi. org/10.4172/2155-9600.1000267

7. Krishna KL, Paridhavi M, Patel JA. Review on nutritional, medicinal and pharmacological properties of papaya (Carica papaya Linn.). Nat Prod Radiance 2008; 7(4):364-373.

8. Fauziya S, Krishnamurthy R. Papaya (Carica papaya): Source material for anticancer. CIBTech J Pharm Sci 2013; 2(1):25-34.

9. Rumiyati, Sismindari dan Ariyani. Effect of the protein fraction of Carica papaya L. leaves on the expressions of P53 and BCL-2 in breast cancer cells line. Maj Farm Indones 2006; 17(4):170176. doi: http://dx.doi.org/10.14499/indonesianjpharm0iss0pp170-176

10. Rashed KN, Fouche G. Anticancer activity of Carica papaya extracts in vitro and phytochemical analysis. Greener J Pharm Pharmacol 2013; 1(1):1-5. doi: http://dx.doi.org/10.15580/ GJPP.2013.1.EB08091310

11. Hasimun P, Ernasari GI. Analgetic activity of papaya (Carica papaya L.) leaves extract. Procedia Chemistry 2014; 13:147-149. doi: http://dx.doi. org/10.1016/j.proche.2014.12.019

12. Nguyen TT, Shaw PN, Parat MO, Hewavitharana AK. Anticancer activity of Carica papaya: A review. Mol Nutr Food Res 2013; 57(1):153-164. doi: http://dx.doi.org/10.1002/mnfr.201200388

13. Emeruwa AC. Antibacterial substance from Carica papaya fruit extract. J Nat Prod 1982; 45(2):123-127. doi: http://dx.doi.org/10.1021/ np50020a002

14. Gupta A, Wambebe CO, Parsons DL. Central and cardiovascular effects of the alcoholic extract of the leaves of Carica papaya. Int J Crude Drug Res 1990; 28(4):257-266. doi: http://dx.doi. org/10.3109/13880209009082830

15. Nugroho A, Heryani H, Choi JS, Park HJ. Identification and quantification of flavonoids in Carica papaya leaf and peroxynitrite-scavenging activity. Asian Pac J Trop Biomed 2017; 7(3):208-213. doi: http://dx.doi.org/10.1016/j.apjtb.2016.12.009

16. Rivera-Pastrana DM, Yahia EM, González-Aguilar GA. Phenolic and carotenoid profiles of papaya fruit (Carica papaya L.) and their contents under low temperature storage. J Sci Food Agric 2010; 90(14):358-2365. doi: http://dx.doi. org $/ 10.1002 /$ jsfa.4092

17. Upgade A, Bhaskar A. Characterization and medicinal importance of phytoconstituents of $C$. papaya from down south Indian region using gas chromatography and mass spectroscopy. Asian J Pharm Clinical Res 2013; 6:101-106.

18. Ong ES. Extraction methods and chemical standardization of botanicals and herbal preparations. J Chromatography B 2004; 812(1-2):23-33. doi: https://dx.doi.org/10.1016/j.jchromb.2004.07.041

19. Lin LZ, Harnly JM. Phenolic compounds and chromatographic profiles of pear skins (Pyrus spp.). J Agric Food Chem 2008; 56(19):90949101. doi: http://dx.doi.org/10.1021/jf8013487

20. Regos I, Urbanella A, Treutter D. Identification and quantification of phenolic compounds from the forage legume sainfoin (Onobrychis viciifolia). J Agric Food Chem 2009; 57(13):5843-5852. doi: http://dx.doi.org/10.1021/jf900625r

21. Fernández-Poyatos MD, Llorent-Martínez EJ, Ruiz-Medina A. Phytochemical composition and antioxidant activity of Portulaca oleracea: influence of the steaming cooking process. Foods 2021; 10(1):94. doi: http://dx.doi.org/10.3390/ foods 10010094

22. Barros L, Pereira E, Calhelha RC, Dueñas M, Carvalho AM, Santos-Buelga C, Ferreira IC. Bioactivity and chemical characterization in hydrophilic and lipophilic compounds of Chenopodium ambrosioides L. J Funct Foods 2013; 5(4):1732-1740. doi: https://dx.doi.org/10.1016/j. jff.2013.07.019

23. Truchado P, Ferreres F, Bortolotti L, Sabatini AG, Tomás-Barberán FA. Nectar flavonol rhamnosides are floral markers of acacia (Robinia pseudacacia) honey. J Agric Food Chem 2008; 56(19):8815-8824. https://doi.org/10.1021/ jf801625t 
24. Sobral F, Calhelha RC, Barros L, Dueñas M, Tomás A, Santos-Buelga C et al. Flavonoid composition and antitumor activity of bee bread collected in northeast Portugal. Molecules 2017; 22(2):248. doi: https://dx.doi.org/10.3390/molecules 22020248

25. Yang L, Wen KS, Ruan X, Zhao YX, Wei F, Wang Q. Response of plant secondary metabolites to environmental factors. Molecules 2018; 23(4):762. doi: https://dx.doi.org/10.3390/molecules 23040762

26. Campostrini E, Glenn DM. Ecophysiology of papaya: a review. Braz J Plant Physiol 2007; 19: 413-424. doi: https://dx.doi.org/10.1590/S167704202007000400010

27. Manach C, Scalbert A, Morand C, Rémésy C, Jiménez L. Polyphenols: food sources and bioavailability. Am J Clin Nutr 2004; 79(5):727-747. doi: https://dx.doi.org/10.1093/ajen/79.5.727

28. David AV, Arulmoli R, Parasuraman S. Overviews of biological importance of quercetin: A bioactive flavonoid. Pharmacogn Rev 2016; 10(20):84-89. doi: https://dx.doi.org/10.4103/0973-7847.194044

29. Dormán G, Flachner B, Hajdú I, András C. Target identification and polypharmacology of nutraceuticals. In: Nutraceuticals. Academic Press 2016:263-286. doi: https://dx.doi.org/10.1016/ B978-0-12-802147-7.00021-8-8
30. Godlewska-Żyłkiewicz B, Świsłocka R, Kalinowska M, Golonko A, Świderski G, Arciszewska Ż et al. Biologically active compounds of plants: etructure-related antioxidant, microbiological and cytotoxic activity of selected carboxylic acids. Materials 2020; 13(19):4454. doi: https://dx.doi. org/10.3390/ma13194454

31. Birková A, Hubková B, Bolerázska B, Mareková M, Čižmárová B. Caffeic acid: a brief overview of its presence, metabolism, and bioactivity. Bioact Compd Health Dis 2020; 3(4):74-81.doi: https:// dx.doi.org/10.31989/bchd.v3i4.692

32. Kim JK, Park SU. A recent overview on the biological and pharmacological activities of ferulic acid. EXCLI J 2019; 18:132-138. doi: http:// dx.doi.org/10.17179/excli2019-1138

33. Soib HH, Ismail HF, Yảakob $H$, Idris MKH, Aziz A. Effect of extraction solvents on antioxidant and wound healing properties of Carica papaya leaves extract. Food Res 2020; 4(S2). doi: https:// dx.doi.org/10.26656/fr.2017.4(S2).S03 